\title{
EDITORIAL
}

\section{Longitudinal surveys - unique opportunities and unique methodological challenges}

PeterLynn,plynn@essex.ac.uk University of Essex, UK

Mick Couper,mcouper@umich.edu

University of Michigan, USA

NicoleWatson,n.watson@unimelb.edu.au

University of Melbourne, Australia

\section{Introduction}

Readers of this journal should hardly need convincing that longitudinal surveys are uniquely valuable (Lynn, 2009a). Longitudinal surveys are able to collect detailed histories over much longer periods of time that would be possible using retrospective recall and are able to reduce recall error by collecting data relatively frequently. Expectations and intentions can be measured before key events take place and before recall of expectations is clouded by subsequent outcomes. When repeated measures are collected, longitudinal surveys enable the analysis of gross change and of unit-level dynamics, including the study of stability or instability. Such analysis approaches are highly informative in many substantive fields. Longitudinal surveys also allow researchers to better identify and understand the time-related characteristics of events, such as frequency, duration and relative timing, an advantage that also assists in the identification of causality.

But all these advantages of longitudinal surveys are realised only if considerable methodological challenges are overcome. These challenges include the need to motivate participants to commit to the study, often over long periods of time, and to minimise and manage panel conditioning. New technologies, changes in the use of technology, increased awareness of - and access to - big data and changing appetite for data linkage all continue to introduce new challenges or change the nature of existing challenges. 


\section{Longitudinal survey methods research}

This special issue of Longitudinal and Life Course Studies is the latest in a series of related initiatives that have provided the impetus for the methodology of longitudinal surveys to become a well-developed and distinct subfield within the discipline of survey methodology. It is now 30 years since the milestone book Panel Surveys (Kasprzyk et al, 1989) was published - the first to devote attention specifically to methods for longitudinal surveys. That book resulted from a symposium held in Washington, DC in 1986. Twenty years later a similar but larger event, the Methodology of Longitudinal Surveys conference, was held at the University of Essex, UK, and spawned an eponymous monograph book (Lynn, 2009b), which was to some extent an update and extension of Panel Surveys. Researchers involved in the 2006 conference (Peter Lynn, Mick Couper, Annette Jäckle), pleased at the success of bringing together researchers from around the world with similar methodological interests, decided to begin a regular series of international workshops on panel survey methods. Their vision was for workshops that would allow for open and productive discussion of methodological challenges facing longitudinal surveys and potential new methods that might offer at least partial solutions. To that end, the workshops were to have a limited number of participants, with some degree of continuity in the attendance list, all sessions were to be plenary, presentations were to be focused on work in progress and ideas under development, and more time was to be set aside for discussion than for presentation. The first of these workshops was held at Essex in 2008, with subsequent workshops in Mannheim, Germany (2010), Melbourne, Australia (2012), Ann Arbor, Michigan (2014) and Berlin, Germany (2016). In 2018 the second International Conference on the Methodology of Longitudinal Surveys was held, 12 years after the first and again at the University of Essex. It is from that conference that the papers in this journal issue emanate.

While we believe the Methodology of Longitudinal Surveys conferences and the Panel Survey Methods Workshops have provided considerable impetus to the development of longitudinal survey methods over the past decade and a half, they have not been alone in doing this. This same period has also seen the birth of this journal, which provides an outlet for specialist longitudinal methodological articles, and a number of survey-specific initiatives.

The European Statistics on Income and Living Conditions (EU-SILC) survey started in 2004 and by 2005 was up to full speed with all 26 EU member states participating. The first four-wave panel data was released in 2008. This was only the second longitudinal survey ever to have been implemented under the European Statistical System and for many of the participating national statistical institutes it was their first experience of a longitudinal survey. Eurostat set up a network of EU-SILC users and experts (Net-SILC1, 2007-10), primarily to develop methodology for the analysis of the EU-SILC data and to develop common tools and approaches for data production. A second network was then commissioned (2011-14), with a work programme that included studies addressing standard error estimation (Berger et al, 2017), sample following rules (Iacovou and Lynn, 2013), attrition (Jenkins and Van Kerm, 2017), and coherence of longitudinal design (Iacovou and Lynn, 2017), while one of the two themes of the third network (Net-SILC3, 20172020 ) is devoted entirely to the study of non-sampling errors, including non-response, attrition, weighting, imputation, data collection modes and interviewer effects. Each 
of the three networks has involved international conferences and a monograph book (Atkinson and Marlier, 2010; Atkinson et al, 2017).

Four of the world's leading household panel surveys hold biennial user conferences which nearly always include a methodological stream alongside presentations of substantive research findings. These are the German Socio-Economic Panel (G-SOEP), ${ }^{1}$ which held its first conference in 1994, the British Household Panel Survey / Understanding Society, ${ }^{2}$ whose conferences began in 1995, the Swiss Household Panel, ${ }^{3}$ whose conferences began in 2001, and the Household, Income and Labour Dynamics in Australia (HILDA) Survey, ${ }^{4}$ whose conferences began in 2003. (The Panel Study of Income Dynamics ${ }^{5}$ holds annual user conferences, but these do not include methodological sessions.) And in 2018 the biennial international conference of the German Family Panel (PAIRFAM), ${ }^{6}$ was devoted to the theme 'Innovations in panel data methods'. Furthermore, regular conferences with broader remits, such as AAPOR, ${ }^{7}$ ISA-R C $33^{8}$ and ESRA ${ }^{9}$ have increasingly included sessions devoted to longitudinal survey methods topics.

\section{Methodological issues}

Though many of the decisions to be made about the design or implementation of a survey are common to both cross-sectional and longitudinal surveys, the implications of a particular design or implementation feature can be very different in the two cases (Lynn and Lugtig, 2017). Consequently, the most appropriate decision can differ. For example, for any survey, a decision is needed about whether to cluster the sample and, if so, to what extent. When face-to-face interviewing is used, a clustered design is typically more efficient. The optimum extent of sample clustering depends primarily on the number of sample elements in each cluster (as this determines field costs) and the relative homogeneity of the clustering units in terms of key survey measures (as this determines the loss in precision due to clustering). Consider this decision about clustering in the context of (1) a crosssectional survey about income, and (2) a longitudinal survey about income dynamics. For the cross-sectional survey, the number of sample elements can be controlled and key survey estimates are measures of income. But for the longitudinal survey, the number of sample elements can be controlled only at the first wave. Thereafter the cost savings due to clustering will decrease due to sample mobility and to estimate them would require complex modelling of geographical mobility patterns. And the key survey estimates are (derived) measures of change in income: relative homogeneity in income does not imply relative homogeneity in income change, or vice versa. Although the range of available design options is the same for the two surveys, it is quite possible that the optimum solution would be different in each case. Most of the survey methods literature deals with design and implementation options for cross-sectional surveys; there remains relatively little literature dealing with the longitudinal survey case.

Furthermore, some design and implementation issues are unique to longitudinal surveys. These include decisions about the need for dynamic sampling to keep the sample representative of the cross-sectional population over time, the interval between data collection waves, the number of waves, methods for tracking and keeping in touch with sample members over time, and whether and how survey questions or procedures should be changed over time. Most of these issues are under-researched. 
In this special issue, Griggs et al (2019) and Herzing et al (2019) both report research that addresses issues in the area of respondent participation.

The article by Griggs et al focuses on high response rates as a desirable outcome but speaks also to the question of how best to use information from earlier waves to better target response-inducing measures to sample members - an active area of current research among longitudinal methods researchers (Lynn, 2017).

Herzing et al address issues of field monitoring in the case of web panels, and how responsive design systems might improve data collection efficiency. The use of targeted designs, responsive designs and other design features to obtain higher response rates and/or better-balanced samples in the longitudinal context is likely to remain an area of active research in the near future, especially in the context of mixed-mode data collection, a direction in which many longitudinal surveys are moving (Bianchi et al, 2017; Voorpostel et al, forthcoming).

Measurement issues also have some distinct features in the case of longitudinal surveys, and the articles by Brown et al (2019) and Ploubidis et al (2019) both contribute to knowledge in this area.

The case for collecting biomarkers in longitudinal social surveys is strong (Kumari and Benzeval, forthcoming), but designs and methods for doing this are still undergoing development. The article by Brown et al contributes to these endeavours by assessing two alternative models for combining the collection of biomarkers in a longitudinal survey.

Survey researchers have long recognised the importance of measurement equivalence in order for comparisons of survey estimates between subgroups to be meaningful. In recent decades, methods to test for measurement equivalence have become ever more sophisticated and these methods have been used by researchers to test for equivalence between important comparison groups such as ethnic groups (Kim et al, 2014) and countries (Davidov et al, 2014; 2018). In longitudinal surveys, measurement equivalence has an extra dimension: as well as being equivalent between subgroups, measurements need to be equivalent within groups over time. Age effects, period effects and survey design changes all have the potential to jeopardise this. The article by Ploubidis et al assesses longitudinal measurement equivalence of a commonly used survey instrument to measure mental health, the Malaise Inventory. The article demonstrates how generalised latent variable measurement models and related extensions can be used to do this and, reassuringly, concludes that the measures appear to be equivalent over three decades of time and ageing, and between two age cohorts.

Understanding how analogous or similar issues are dealt with in other fields or disciplines is often fruitful. Smith and Yung (2019) identify parallels between longitudinal social surveys and repeated business surveys and their inspiring article suggests several ways in which methodologists involved in either type of survey might learn from the other. The methodological topics addressed in their article cover the full survey process, from sample design, through data collection to analysis.

Finally, the article by Bergmann et al (2019) addresses an important issue in the area of survey quality control, namely the identification of fake interviews and consequent remedial action. Though thankfully a relatively rare problem, fake interviews can have serious consequences, particularly in a longitudinal survey, so efforts to identify them are justified. In the article, the authors use learning from one wave of a longitudinal survey to inform action at the subsequent wave. 
We hope that this special issue of Longitudinal and Life Course Studies makes some useful contributions to knowledge regarding the methodology of longitudinal surveys. However, much remains unknown, or unclear, about how best to design and implement these valuable - and expensive - surveys. We trust that funders will have the foresight to sponsor, and that researchers will create and take opportunities to carry out, methodological research that will enable the potential value of longitudinal surveys to be maximised.

\section{Notes}

${ }^{1}$ www.diw.de/en/soep [Accessed 27 August 2019].

${ }^{2}$ www.understandingsociety.ac.uk [Accessed 27 August 2019].

${ }^{3}$ https://forscenter.ch/projects/swiss-household-panel/ [Accessed 27 August 2019].

${ }^{4}$ https://melbourneinstitute.unimelb.edu.au/hilda [Accessed 27 August 2019].

${ }^{5}$ https://psidonline.isr.umich.edu/ [Accessed 27 August 2019].

${ }^{6}$ https://www.pairfam.de/en/ [Accessed 27 August 2019].

7 www.aapor.org/Conference-Events/Annual-Meeting.aspx [Accessed 27 August 2019].

${ }^{8}$ http://rc33.org/conferences/ [Accessed 27 August 2019].

9 https://www.europeansurveyresearch.org/conferences/esra-biennial-conference [Accessed 27 August 2019].

\section{Conflict of interest}

The authors declare that there is no conflict of interest.

\section{References}

Atkinson, A.B. and Marlier, E. (eds) (2010) Income and living conditions in Europe, Luxembourg: EU Publications.

Atkinson, A.B., Guio, A.-C. and Marlier, E. (eds) (2017) Monitoring social inclusion in Europe, Luxembourg: EU Publications.

Berger, Y., Osier, G. and Goedemé, T. (2017) Standard error estimation and related sampling issues, In A.B. Atkinson,A.-C. Guio and E. Marlier (eds), Monitoring social inclusion in Europe, Luxembourg: EU Publications, pp. 465-78.

Bergmann, M., Schuller, K. and Malter, F. (2019) Preventing interview falsifications during fieldwork in the Survey of Health, Ageing and Retirement in Europe (SHARE), Longitudinal and Life Course Studies, 10(4): 513-30. doi: 10.1332/1757 95919X15694136530293

Bianchi, A., Biffignandi, S. and Lynn, P. (2017) Web-face-to-face mixed mode design in a longitudinal survey: effects on participation rates, sample composition, and costs, Journal of Official Statistics, 33(2): 385-408. doi: 10.1515/jos-2017-0019

Brown, M., Gilbert, E., Calderwood, L., Taylor, K. and Morgan, H. (2019) Collecting biomedical and social data in a longitudinal survey:A comparison of two approaches, Longitudinal and Life Course Studies, 10(4): 453-69. doi: 10.1332/175795919X15 694156772013

Davidov, E., Dülmer, H., Cieciuch, J., Kuntz, A., Seddig, D. and Schmidt, P. (2018) Explaining measurement nonequivalence using multilevel structural equation modeling: the case of attitudes toward citizenship rights, Sociological Methods E Research, 47(4): 729-60. doi: 10.1177/0049124116672678 
Davidov, E., Meuleman, B., Cieciuch,J., Schmidt, P. and Billiet, J. (2014) Measurement equivalence in cross-national research, Annual Review of Sociology, 40: 55-75. doi: 10.1146/annurev-soc-071913-043137

Griggs, A., Powell, R., Keeney, J., Waggy, M., Harris, K., Halpern, C. and Dean, S. (2019) Research note: A prenotice greeting card's impact on response rates and response time, Longitudinal and Life Course Studies, 10(4): 421-31. doi: 10.1332/17 $5795919 X 15683587984841$

Herzing, J.M.E., Vandenplas, C. and Axenfeld, J.B. (2019) A data-driven approach to monitoring data collection in an online panel, Longitudinal and Life Course Studies, 10(4): 433-52. doi: 10.1332/175795919X15694136006114

Iacovou, M. and Lynn, P. (2013) Implications of the EU-SILC "following rules" (and their implementation) for longitudinal analysis, Eurostat statistical working paper, Luxembourg: Publications Office of the European Union. doi: 10.2785/45341

Iacovou, M. and Lynn, P. (2017) Design and implementation issues to improve the research value of the longitudinal component of EU-SILC, In A.B. Atkinson, A.-C. Guio and E. Marlier (eds), Monitoring social inclusion in Europe, Luxembourg: EU Publications, pp. 479-97.

Jenkins, S.P. and Van Kerm, P. (2017) How does attrition affect estimates of persistent poverty rates? The case of EU-SILC, In A.B. Atkinson, A.-C. Guio and E. Marlier (eds), Monitoring social inclusion in Europe, Luxembourg: EU Publications, pp. 401-17.

Kasprzyk, D., Duncan, G., Kalton, G. and Singh, M.P. (eds) (1989) Panel surveys, New York: Wiley.

Kim, G., Sellbom, M. and Ford, K.-L. (2014) Race/ethnicity and measurement equivalence of the Everyday Discrimination Scale, Psychological Assessment, 26(3): 892-900. doi: 10.1037/a0036431

Kumari, M. and Benzeval, M. (forthcoming) Collecting biomarker data in longitudinal surveys, In P. Lynn (ed), Advances in longitudinal survey methodology, Chichester: Wiley-Blackwell.

Lynn, P. (2009a) Methods for longitudinal surveys, In P. Lynn (ed), Methodology of Longitudinal Surveys, Chichester:Wiley, pp. 1-19.

Lynn, P. (ed) (2009b) Methodology of longitudinal surveys, Chichester: Wiley.

Lynn, P. (2017) From standardised to targeted survey procedures for tackling nonresponse and attrition, Survey Research Methods, 11(1): 93-103. doi: 10.18148/ srm/2017.v11i1.6734

Lynn, P. and Lugtig, P.J. (2017) Total survey error for longitudinal surveys, In P.P. Biemer, E.D. de Leeuw, S. Eckman, B. Edwards, F. Kreuter, L.E. Lyberg, N.C. Tucker and B.T. West (eds), Total survey error in practice, Hoboken, NJ:Wiley, pp. 279-98.

Ploubidis, G., McElroy, E. and Moreira, H. (2019) A longitudinal examination of the measurement equivalence of mental health assessments in two British birth cohorts, Longitudinal and Life Course Studies, 10(4): 471-89. doi: 10.1332/175795 919X15683588979486

Smith, P.A. and Yung, W. (2019) A review and evaluation of the use of longitudinal approaches in business surveys, Longitudinal and Life Course Studies, 10(4): 491-511. doi: 10.1332/175795919X15694142999134

Voorpostel, M., Lipps, O. and Roberts, C. (forthcoming) Mixing modes in household panel surveys: recent developments and new findings, In P. Lynn (ed), Advances in longitudinal survey methodology, Wiley-Blackwell. 